Article

\title{
Calcium Chloride-Assisted Segregation Reduction of Chromite: Influence of Reductant Type and the Mechanism
}

\author{
Dawei Yu * (1) and Dogan Paktunc* (1) \\ CanmetMINING, Natural Resources Canada, 555 Booth Street, Ottawa, ON K1A 0G1, Canada \\ * Correspondence: dawei.yu@hotmail.com (D.Y.); dogan.paktunc@canada.ca (D.P.); \\ Tel.: +1-613-947-8024 (D.Y.); +1-613-947-7061 (D.P.)
}

Received: 19 December 2017; Accepted: 26 January 2018; Published: 29 January 2018

\begin{abstract}
This paper describes an innovative process for the production of ferrochromium alloy via segregation reduction of chromite at $1300{ }^{\circ} \mathrm{C}$ in the presence of calcium chloride. Both charcoal and petroleum coke were used as the reductant. Individual polycrystalline ferrochrome carbide particles were produced, with their particle size and shape resembling that of the starting carbon particles. Interactions among calcium chloride, clinochlore, and chromite resulted in the formation of Ca-bearing chromite, wadalite, and gaseous chlorides. Monocrystalline ferrochrome carbide whiskers were formed only when charcoal in the presence of calcium chloride was used to reduce the chromite fraction containing large amounts of siliceous gangue. Incorporating thermodynamic evaluations, a possible segregation reduction mechanism is suggested based on the characterization of the products using scanning electron microscopy, energy dispersive spectroscopy, X-ray powder diffraction, and electron probe microanalysis, combined with thermogravimetric analysis. Metallization within chromite particles was minimized, which is suggested to be due to the ubiquitous presence of molten and gaseous calcium chloride between the chromite and carbon particles, and especially in the porous rim of the chromite particles during reduction, resulting in restricted metallization only on the carbon particles.
\end{abstract}

Keywords: chromite; ferrochrome; carbothermic reduction; segregation; $\mathrm{CaCl}_{2}$; wadalite

\section{Introduction}

Ferrochromium alloy, mainly in the form of high carbon ferrochrome, is produced by the carbothermic smelting reduction of chromite in a submerged arc furnace (SAF) at an operating temperature higher than $1600{ }^{\circ} \mathrm{C}$ [1]. Chromite mineral is spinel $\left(\mathrm{A}^{2+}{ }_{1} \mathrm{~B}^{3+}{ }_{2} \mathrm{O}_{4}\right)$ with its tetrahedral sites occupied by the divalent ions of $\mathrm{Fe}^{2+}$ and $\mathrm{Mg}^{2+}$ and its octahedral sites by the trivalent ions of $\mathrm{Cr}^{3+}$, $\mathrm{Fe}^{3+}$, and $\mathrm{Al}^{3+}[2,3]$. The SAF operation is energy intensive and consumes specific electric energy (SEC) in the range of 2.4-4.8 MWh per ton of ferrochrome produced [4]. Energy efficiency of ferrochrome production can be significantly improved by reduction at a lower temperature in the solid regime; that is, solid carbothermic reduction. However, the unique challenges associated with the inevitable metallization within the solid chromite particles and the formation of an impervious and refractory oxide layer (e.g., $\mathrm{MgAl}_{2} \mathrm{O}_{4}$ ) on the chromite particles during solid reduction of chromite [5-10] not only significantly limits the reduction rate, but also imposes significant difficulties in achieving high metal recovery in the form of ferrochrome alloy without utilizing a SAF for the subsequent separation of metals from the unwanted gangue/slag.

This paper describes an innovative segregation reduction process operated at a much lower temperature $\left(\sim 1300{ }^{\circ} \mathrm{C}\right)$ for directly producing ferrochrome without the need of a SAF, thereby eliminating the heavy reliance on electricity and potentially further reducing the ferrochrome 
production cost. Both charcoal and petroleum coke were employed in this study as the carbonaceous reductant. The chlorination system with the addition of $\mathrm{CaCl}_{2}$ was employed to first segregate the reducible $\mathrm{Cr}$ and Fe species from the chromite particles before reduction and metallization on the carbon particles. This promoted the formation of individual alloy particles, allowing for subsequent easier separation. The formation of the mobile gas species of $\mathrm{Cr}$ and $\mathrm{Fe}$ in the carbochlorination process has been studied [11-15] to treat low-grade chromite ores at temperatures less than $1000{ }^{\circ} \mathrm{C}$; this increases their $\mathrm{Cr}$ :Fe ratio by selectively removing Fe from the chromite ores in the form of $\mathrm{FeCl}_{3}$. This process involves the presence of chlorine gas and a carbonaceous reductant (i.e., solid carbon [11] or gaseous CO [13]). When CO is used as the reductant, the reaction can be represented by Equation (1) [15]. The chlorinating product of chromium oxide is expected to be $\mathrm{CrCl}_{3}$, which can be represented by the reaction in Equation $(2)[13,16]$. The volatility of chlorides is dependent upon the temperature, which can be expressed as the equilibrium vapor pressure as a function of temperature (Figure 1).

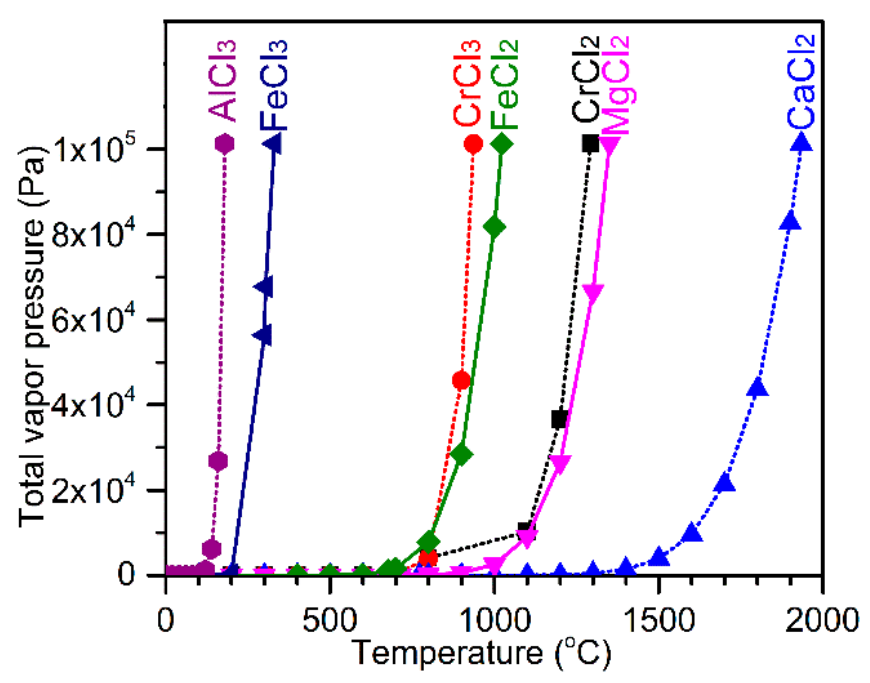

Figure 1. Equilibrium vapor pressure of the chloride of interest plotted using data from FactSage [17].

$$
\begin{gathered}
(2 / 3) \mathrm{FeCr}_{2} \mathrm{O}_{4}+\mathrm{Cl}_{2}(\mathrm{~g})+(2 / 3) \mathrm{CO}(\mathrm{g})=(2 / 3) \mathrm{FeCl}_{3}+(2 / 3) \mathrm{CO}_{2}(\mathrm{~g})+(2 / 3) \mathrm{Cr}_{2} \mathrm{O}_{3} \\
1 / 3 \mathrm{Cr}_{2} \mathrm{O}_{3}+\mathrm{Cl}_{2}(\mathrm{~g})+\mathrm{CO}(\mathrm{g})=2 / 3 \mathrm{CrCl}_{3}+\mathrm{CO}_{2}
\end{gathered}
$$

Since the accidental discovery of the segregation phenomenon in 1923 [18], segregation roasting/reduction in the presence of $\mathrm{NaCl}$ has been investigated extensively for treating refractory copper ores [19]. Segregation reduction was later adopted and studied for treating iron oxide ores [20,21] and nickel oxide ores [22-27]. The segregation reduction mechanism incorporates four general steps. First, $\mathrm{HCl}$ is produced from the pyrohydrolysis of $\mathrm{NaCl}$ in the presence of silica or siliceous gangue and water vapor, which can be presented by the reaction in Equation (3) $[19,26]$. Second, the metal $(\mathrm{Me})$ oxides are chloridized by $\mathrm{HCl}$, forming volatile metal chlorides and, in the meantime, regenerating $\mathrm{H}_{2} \mathrm{O}$ vapor (Equation (4)). Third, $\mathrm{H}_{2}$ gas is generated from the reduction of $\mathrm{H}_{2} \mathrm{O}$ vapor by carbon (Equation (5)). Fourth, volatile chlorides are absorbed onto the surface of carbon particles and reduced by $\mathrm{H}_{2}$ gas, regenerating $\mathrm{HCl}$ (Equation (6)). Since no literature exists on the segregation reduction of chromite, one important objective of this study is to investigate the carbothermic segregation reduction mechanism of chromite in the presence of $\mathrm{CaCl}_{2}$.

$$
\begin{gathered}
2 \mathrm{NaCl}(\mathrm{s})+\mathrm{SiO}_{2}(\mathrm{~s})+\mathrm{H}_{2} \mathrm{O}(\mathrm{g})=\mathrm{Na}_{2} \mathrm{O} \cdot \mathrm{SiO}_{2}(\mathrm{~s})+2 \mathrm{HCl}(\mathrm{g}) \\
\mathrm{MeO}(\mathrm{s})+2 \mathrm{HCl}(\mathrm{g})=\mathrm{MeCl}_{2}(\mathrm{~s})+\mathrm{H}_{2} \mathrm{O}(\mathrm{g})
\end{gathered}
$$




$$
\begin{aligned}
& \mathrm{C}(\mathrm{s})+2 \mathrm{H}_{2} \mathrm{O}(\mathrm{g})=2 \mathrm{H}_{2}(\mathrm{~g})+\mathrm{CO}_{2}(\mathrm{~g}) \\
& \mathrm{MeCl}_{2}(\mathrm{~s})+\mathrm{H}_{2}(\mathrm{~g})=\mathrm{Me}+2 \mathrm{HCl}(\mathrm{g})
\end{aligned}
$$

\section{Materials and Methods}

\subsection{Materials}

The as-received chromite ore was sieved to produce four size fractions that were used for the study (Table 1). Based on electron probe microanalysis (EPMA), the average composition of the chromite can be represented as $\left(\mathrm{Fe}^{2+}{ }_{0.5} \mathrm{Mg}_{0.5}\right)\left(\mathrm{Cr}_{1.4} \mathrm{Fe}^{3+}{ }_{0.1} \mathrm{Al}_{0.5}\right) \mathrm{O}_{4}$. As shown in Table 1, smaller size fractions contain higher amounts of gangue minerals, which are clinochlore $(\mathrm{Mg}, \mathrm{Fe})_{5} \mathrm{Al}\left(\mathrm{Si}_{3} \mathrm{Al}\right) \mathrm{O}_{10}(\mathrm{OH})_{8}$, phlogopite $\mathrm{KMg}_{3}\left(\mathrm{Si}_{3} \mathrm{Al}\right) \mathrm{O}_{10}(\mathrm{OH})_{2}$, and magnesite $\left(\mathrm{MgCO}_{3}\right)$. The granular charcoal that was used in this study had a $12 \mathrm{wt} \%$ mass loss on drying at $130{ }^{\circ} \mathrm{C}$ and contained total carbon of $85.3 \mathrm{wt} \%$ based on LECO analysis. The charcoal was ground and sieved to produce three size fractions: 75-105 $\mu \mathrm{m}, 105-180 \mu \mathrm{m}$, and 180-300 $\mu \mathrm{m}$. Petroleum coke in the size range of 75-105 $\mu \mathrm{m}$ was used, which contained $85.1 \mathrm{wt} \%$ carbon. Finely ground anhydrous $\mathrm{CaCl}_{2}$ powder was used as the chloridizing agent.

Table 1. Mineralogical compositions of the chromite ores of four size fractions.

\begin{tabular}{ccccc}
\hline Particle Size & Chromite & Clinochlore & Phlogopite & Magnesite \\
\hline $\boldsymbol{\mu m}$ & wt \% & wt \% & wt \% & wt \% \\
\hline $37-75$ & 67.8 & 23.3 & 4.8 & 4.1 \\
$75-105$ & 85.9 & 10.7 & 2.3 & 1.1 \\
$105-180$ & 90.2 & 8.7 & 1.1 & 0 \\
$180-300$ & 91.2 & 8.6 & 0.2 & 0 \\
\hline
\end{tabular}

\subsection{Electric Tube Furnace Tests}

The ore sample, typically $10 \mathrm{~g}$, was mixed with pre-determined amounts of reductant and anhydrous $\mathrm{CaCl}_{2}$ before multiple cylindrical pellets were prepared using a $13 \mathrm{~mm}$ die set. A pressure of $0.7 \mathrm{MPa}$ was applied for $15 \mathrm{~s}$ to make the pellets with a bulk density of approximately $1.2 \mathrm{~g} / \mathrm{mL}$. With a constant Ar flow of $500 \mathrm{~mL} / \mathrm{min}$, the pellets were subjected to heating to $1300^{\circ} \mathrm{C}$ in an electric tube furnace at a rate of $6.25^{\circ} \mathrm{C} / \mathrm{min}$, and held for $2-3 \mathrm{~h}$. The reduced sample was cooled inside the furnace at a maximum rate of the furnace capacity to room temperature before taking the sample out. The off-gas was continuously analyzed by a gas analyzer (ABB EL3020, ABB, Cary, NC, USA) during heating.

\subsection{Thermogravimetric Analysis}

Thermogravimetric analysis (TG-DSC-MS) was conducted using a NETZSCH STA 449C Simultaneous Thermal Analyzer (Netzsch Gerätebau GmbH, Selb, Germany) coupled with a NETZSCH QMS $403 \mathrm{C}$ Aeolos Mass Spectrometer (Netzsch Gerätebau GmbH, Selb, Germany) to further investigate the segregation reduction mechanism. For each test, the sample was placed inside an alumina crucible (O.D. $6.8 \mathrm{~mm}$ ), which was then covered with an alumina lid and loaded into the TG-DSC chamber. Vacuum was applied to remove air before filling the chamber with Ar gas (5 $\mathrm{N}$ pure). The sample was subjected to heating in an Ar flow of $100 \mathrm{~mL} / \mathrm{min}$ according to the pre-programmed temperature profile.

\subsection{Analytical Methods}

Polished sections of the samples were prepared and examined using a scanning electron microscope (SEM, Hitachi S-3200N, Hitachi Corporation, Tokyo, Japan) with an accelerating voltage of $20 \mathrm{kV}$, which was coupled with an energy dispersive spectrometer (Quantax EDS, Bruker, Karlsruhe, Germany). Surface morphology of the samples was also examined by firstly water-leaching the reduced 
products to remove the water-soluble components (i.e., chlorides), followed by drying to remove moisture before spreading the dried powder sample on a double-sided carbon tape as a monolayer for SEM-EDS analysis. EPMA was also performed on selected polished sections for quantitative chemical analysis on individual phases using a JEOL JXA-8900 microprobe coupled with wavelength dispersive spectrometers (WDS). Analysis was conducted using an accelerating voltage of $20 \mathrm{kV}$ and a beam current of $26 \mathrm{nA}$. Elements were acquired using analyzing crystals LIF for $\mathrm{Cr} \mathrm{K} \alpha, \mathrm{Mn} \mathrm{K} \alpha, \mathrm{Fe} \mathrm{K} \alpha$; TAP for Al K $\alpha$; PETJ for Ca K $\alpha, \mathrm{K} K \alpha$; TAPH for Mg K $\alpha$, Na K $\alpha$, Si K $\alpha$; and LIFH for Ti K $\alpha$. Powder X-ray diffraction (XRD) analysis was performed using a Rigaku D/MAX 2500 rotating-anode powder diffractometer with $\mathrm{Cu} \mathrm{K} \alpha$ radiation at $40 \mathrm{kV}, 200 \mathrm{~mA}$.

\section{Results and Discussions}

\subsection{Effect of Chromite Particle Size}

The effect of the chromite particle size was evaluated by conducting electric tube furnace tests at $1300{ }^{\circ} \mathrm{C}$ on $13 \mathrm{~mm}$ pellets composed of $10.0 \mathrm{~g}$ chromite $(75-105 \mu \mathrm{m}$ or $180-300 \mu \mathrm{m}), 2.2 \mathrm{~g}$ charcoal (75-105 $\mu \mathrm{m}$ ), and $3.0 \mathrm{~g} \mathrm{CaCl}_{2}$. The off-gas $\mathrm{CO}$ and $\mathrm{CO}_{2}$ concentrations are plotted in Figure 2 along with the temperature profiles for comparison. The $\mathrm{CO}_{2}$ peak at about $40 \mathrm{~min}\left(500{ }^{\circ} \mathrm{C}\right)$ was due to the decomposition of magnesite [10]. Higher evolution of $\mathrm{CO}_{2}$ for the reduction of 75-105 $\mu \mathrm{m}$ chromite was due to the presence of higher amounts of magnesite. Carbothermic reduction of chromite by charcoal resulted in the evolution of massive $\mathrm{CO}$ and minor $\mathrm{CO}_{2}$ gases, peaking at $160 \mathrm{~min}\left(1300{ }^{\circ} \mathrm{C}\right)$. Interestingly, the CO peak for 180-300 $\mu \mathrm{m}$ chromite reduction was significantly higher at the beginning of reduction, although the chromite particle size range was significantly higher. It appears that using a larger particle size range of chromite was beneficial on the aspect of reduction kinetics. Cross-sections and surface morphologies of the reduced products are illustrated in Figure 3. The white particles are the individual ferrochrome alloy particles that were formed from the segregation reduction of chromite in the presence of $\mathrm{CaCl}_{2}$. The grey particles are the residual gangue and reduced chromite particles that are porous and composed of mainly $\mathrm{MgAl}_{2} \mathrm{O}_{4}$ and $\mathrm{MgO}$ phases, in which little alloy phase is present. This demonstrates that $\mathrm{CaCl}_{2}$ is very effective in selectively removing the $\mathrm{Cr}$ and $\mathrm{Fe}$ from chromite followed by metallization on the carbon particles while minimizing the alloy formation from within the chromite particles.

A very small portion of the reduced chromite particles still contained a number of discrete alloy particles that were generally less than $5 \mu \mathrm{m}$ in size. Figure 4 illustrates the backscattered electron (BSE) image and elemental mapping of a typical chromite particle of this type. The micron-sized discrete alloy particles were located in a zone close to the center of the chromite particle and were invariably Fe-rich. The elemental mapping image in Figure 4 shows that the reduced chromite particle was composed of mainly $\mathrm{MgAl}_{2} \mathrm{O}_{4}$ and $\mathrm{MgO}$ phases, with the $\mathrm{MgAl}_{2} \mathrm{O}_{4}$ phase concentrated on the outer edge. It also shows the presence of likely molten siliceous gangue (purple) that wetted the chromite surface. Figure 5 illustrates a partially reduced chromite particle, demonstrating an intermediate stage in the formation of the discrete Fe-rich alloy particles. Within each chromite particle, segregation by $\mathrm{CaCl}_{2}$ and reduction/metallization of the $\mathrm{Cr}$ and $\mathrm{Fe}$ are two competing processes. At the beginning of segregation reduction, the chromite particles were surrounded by gaseous or molten $\mathrm{CaCl}_{2}$. Segregation took place effectively resulting in the removal of $\mathrm{Cr}$ and $\mathrm{Fe}$ from the chromite particle, forming a reacted rim surrounding the unreacted chromite core. The rim became thicker with the progress of segregation reduction, which was accompanied by the shrinking unreacted core. At some point, the rim became appreciably thick and the chloridizing agent became less effective in segregating the unreacted core. The oxygen potential within the chromite was eventually low enough to cause preferential Fe reduction and metallization within the chromite core, forming an Fe-rich alloy whisker surrounded by a secondary chromite zone that was Fe-deficient [10]. This Fe-deficient chromite appears as a darker zone surrounding the white whisker-shaped Fe-rich alloy as shown in Figure 5. The chloridizing agent was incapable of segregating the already-formed alloy phase. Therefore, the Fe-rich alloy phase 
remained in the chromite particle when the chromite core continued to shrink, which would disappear as shown in Figure 4. It appears that the Fe-rich alloy gradually changed its shape from whiskers to spheres driven by the minimization of the surface energy of each individual alloy particle, eventually forming the micron-sized spherical Fe-rich alloy particles.

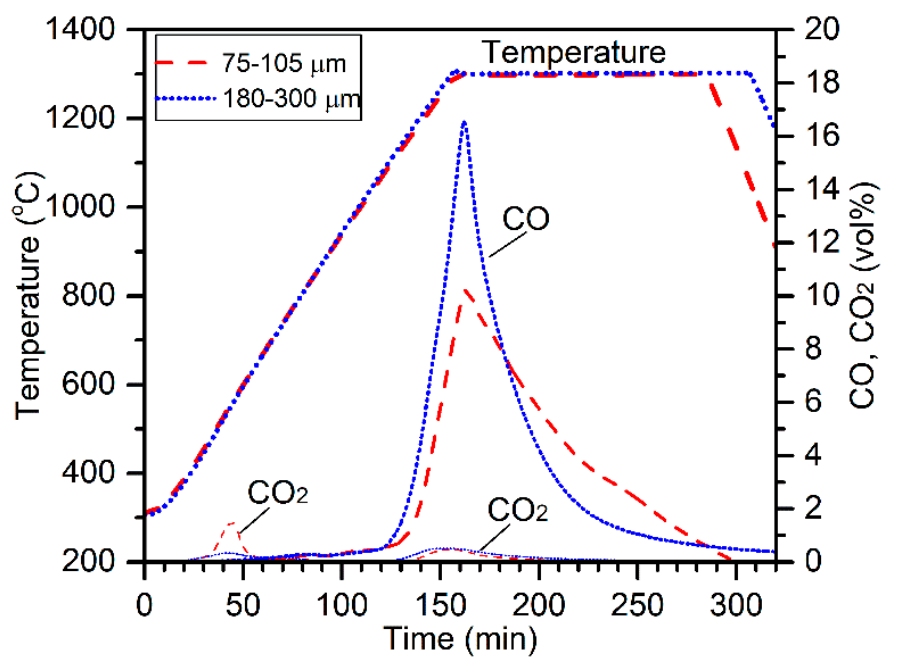

Figure 2. Temperature profiles and off-gas $\mathrm{CO}$ and $\mathrm{CO}_{2}$ concentrations for the tests with the variation of chromite particle size.
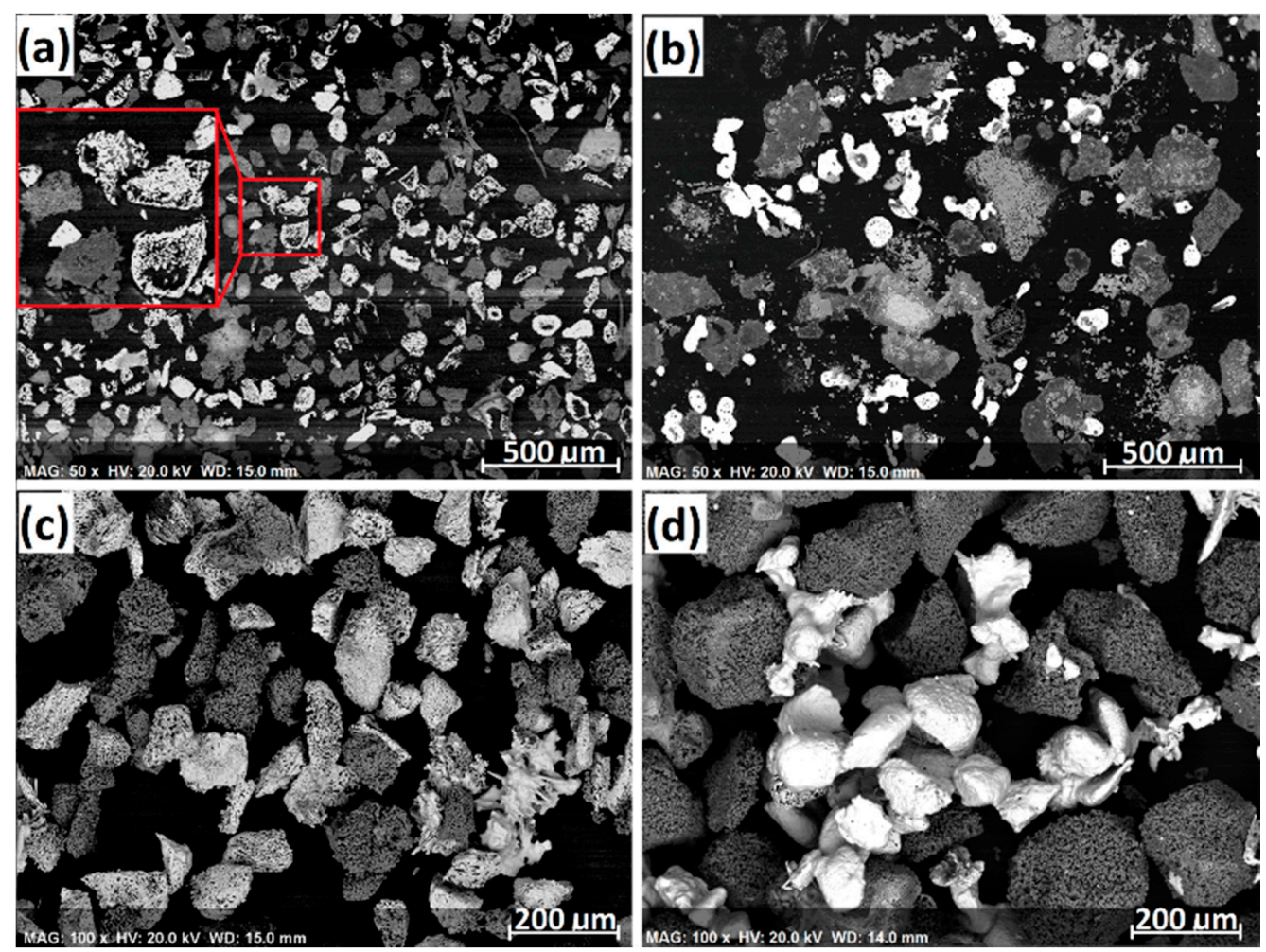

Figure 3. Backscattered electron (BSE) micrographs of the products formed using 75-105 $\mu \mathrm{m}$ chromite $(\mathbf{a}, \mathbf{c})$ and 180-300 $\mu \mathrm{m}$ chromite $(\mathbf{b}, \mathbf{d})$. Photomicrographs a and $\mathrm{b}$ represent polished section surfaces while $\mathrm{c}$ and $\mathrm{d}$ show surface morphologies of the reduced products. 

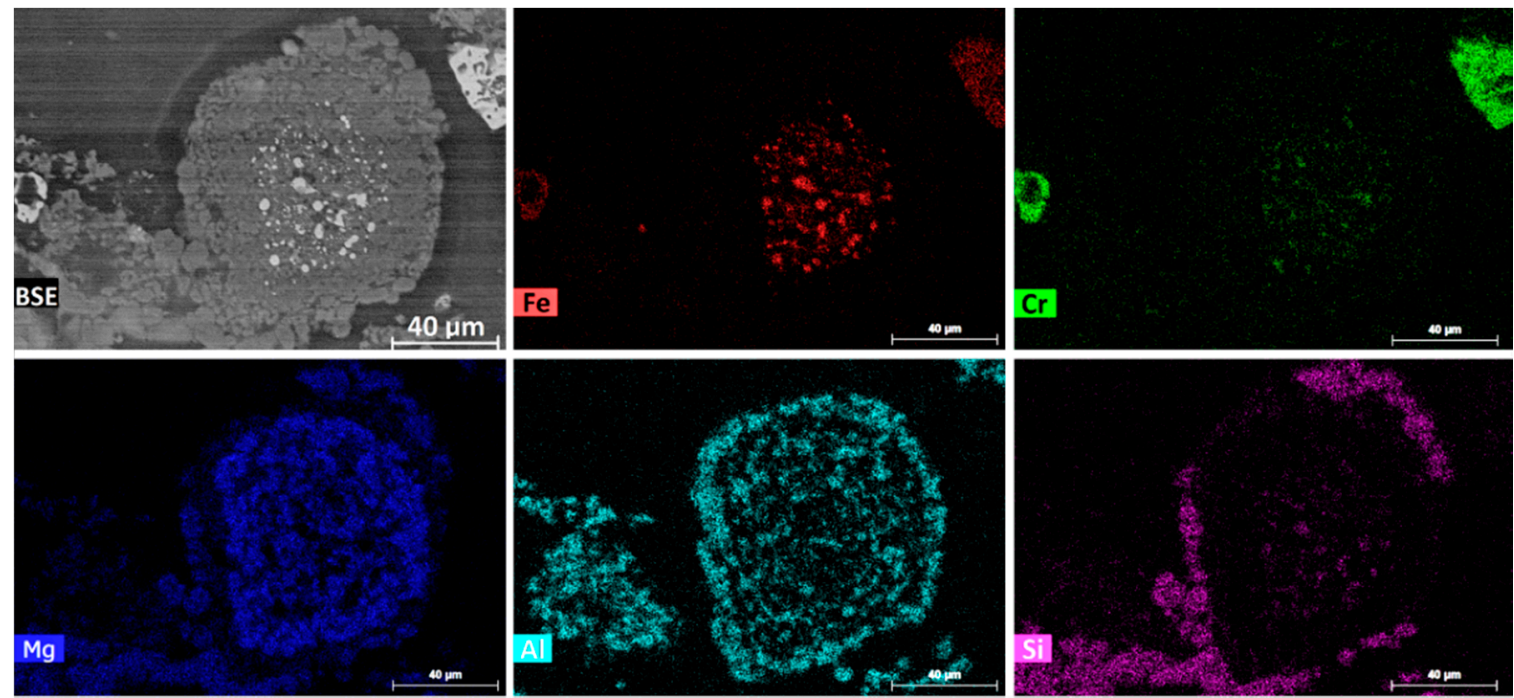

Figure 4. BSE and elemental mapping of a reduced chromite particle $(75-105 \mu \mathrm{m})$ in which discrete Fe-rich ferrochrome alloy particles are present.

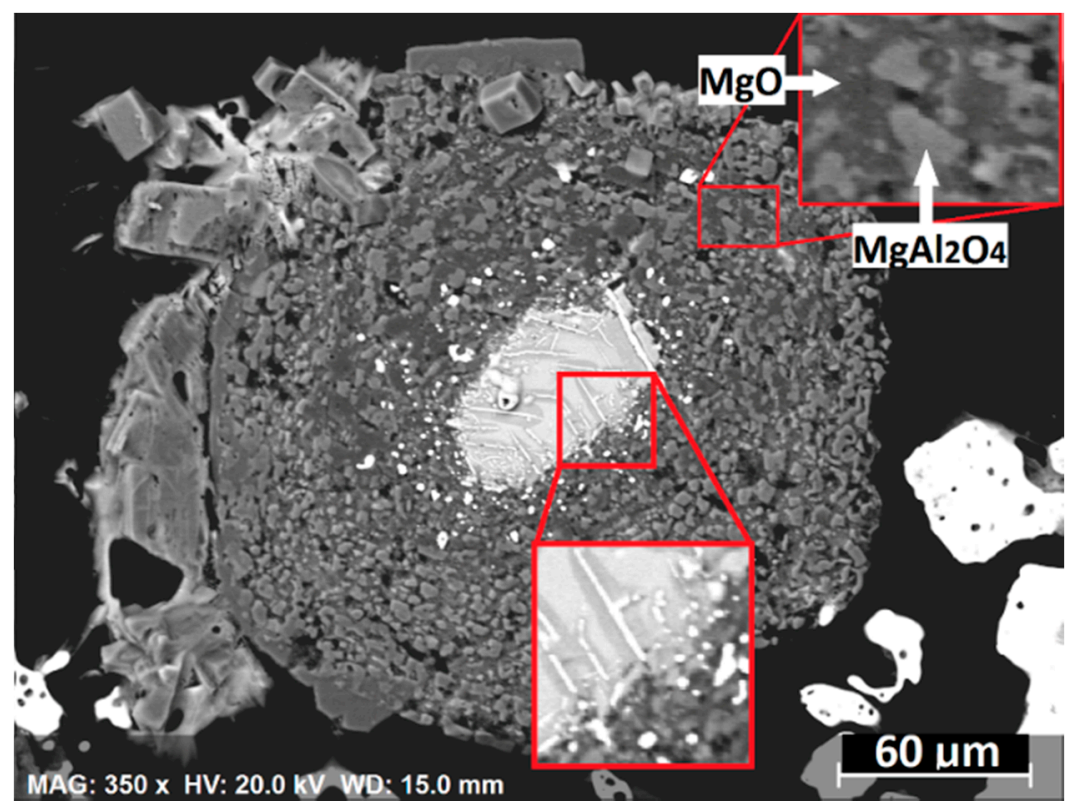

Figure 5. BSE image of a partially reduced chromite particle $(180-300 \mu \mathrm{m})$ with a chromite core, illustrating the mechanism for the formation of discrete Fe-rich ferrochrome alloy particles.

\subsection{Effect of Charcoal Particle Size}

Electric furnace tests were performed on pellets made of 37-75 $\mu \mathrm{m}$ chromite fraction mixed with $22 \mathrm{wt} \%$ charcoal $(105-180 \mu \mathrm{m}$, or $180-300 \mu \mathrm{m})$ and $30 \mathrm{wt} \% \mathrm{CaCl}_{2}$. Based on the off-gas analysis as shown in Figure 6, a coarser particle size range of the charcoal resulted in a slower reduction rate. Because of the lower concentrations of $\mathrm{Cr}$ and Fe oxides in the 37-75 $\mu \mathrm{m}$ chromite fraction, a much lower amount of charcoal was required to achieve complete reduction. The residual charcoal occurred as carbon cores in the ferrochrome particles, which is shown in Figure 7. The fractured surface of the alloy particle in this figure reveals the existence of gaps between the slightly porous alloy shell and the carbon core. Alloy nucleation can be found in this gap on the surface of the carbon core, indicating the 
inward transportation of $\mathrm{Cr}$ and Fe species through the pores of the alloy shell onto the carbon surface, where nucleation took place.

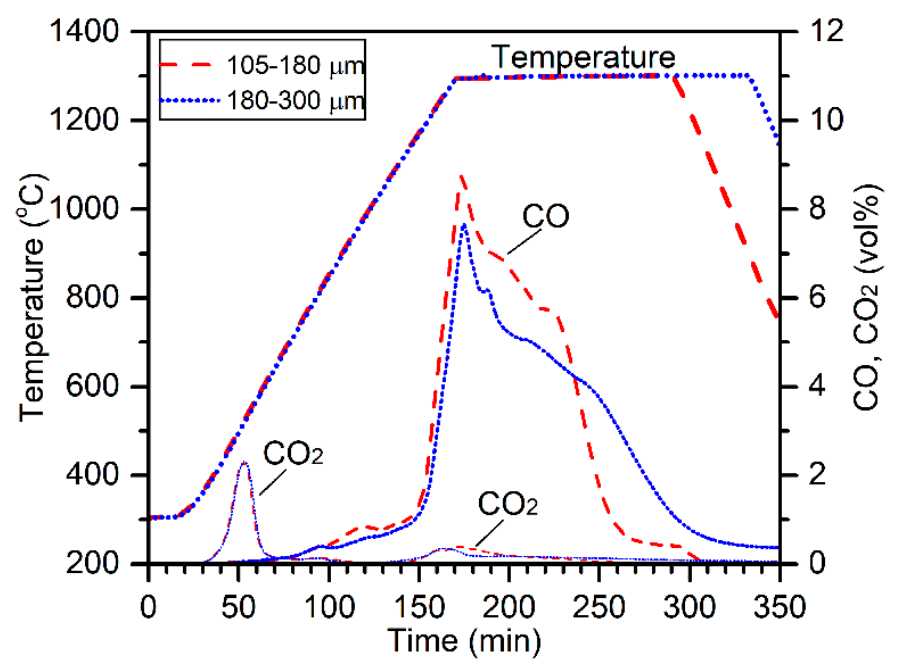

Figure 6. Temperature profiles and off-gas $\mathrm{CO}$ and $\mathrm{CO}_{2}$ concentrations for the tests with the variation of charcoal particle size.

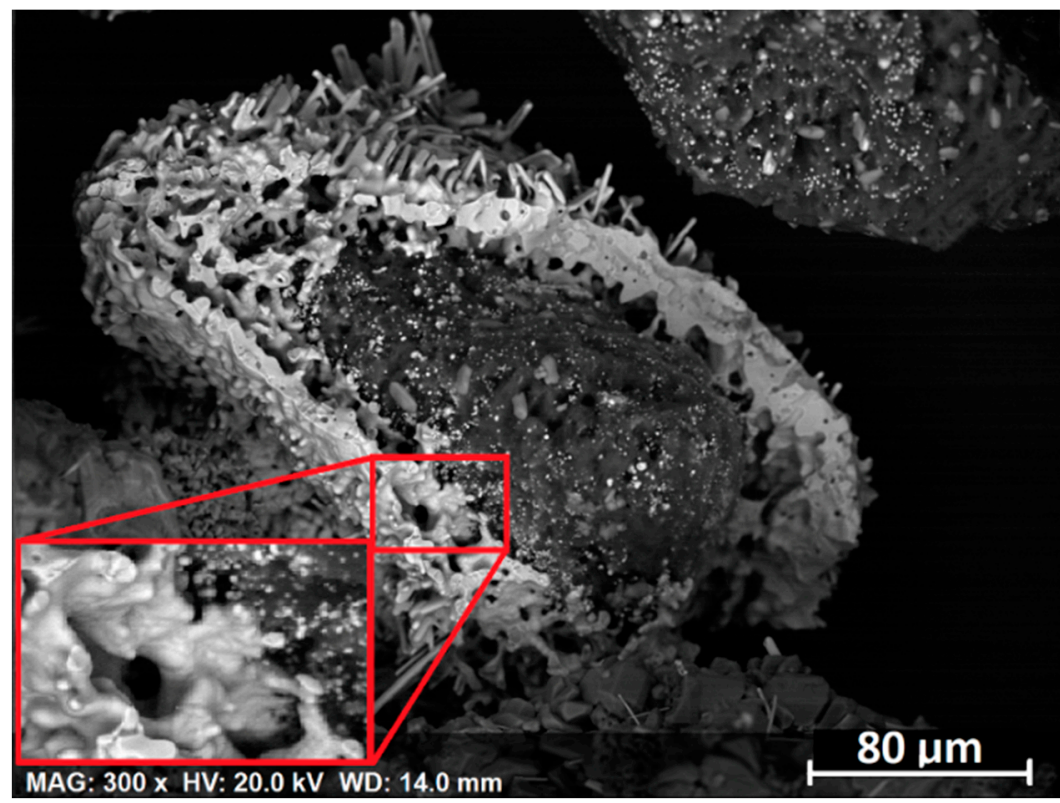

Figure 7. Fractured surface of a ferrochrome particle produced from chromite reduction by $180-300 \mu \mathrm{m}$ charcoal, revealing the residual charcoal core with the presence of alloy nucleation on the core surface.

\subsection{Influence of Pelletization}

The segregation reduction rate of the chromite can be significantly influenced by the porosity of the sample mixture, which was evaluated by comparing the reduction tests at $1300{ }^{\circ} \mathrm{C}$ using both pellets and powders composed of 37-75 $\mu \mathrm{m}$ chromite, $105-180 \mu \mathrm{m}$ charcoal ( $22 \mathrm{wt} \%$ of chromite), and ground anhydrous $\mathrm{CaCl}_{2}$ (30 wt \% of chromite). Because the powder sample was loosely packed during reduction, its porosity was appreciably higher than that of the pellets, meaning a longer distance for the segregation and transportation of $\mathrm{Cr}$ and Fe species from a chromite particle to its adjacent charcoal particles. As expected, the reduction rate was comparatively higher for the test with pellets (Figure 8) because of the reduced spacing between the chromite and charcoal particles. Two stages can 
be identified for the reduction of pellets at $1300{ }^{\circ} \mathrm{C}$, indicated by the sudden change in the trend of the $\mathrm{CO}$ profile. In comparison, the $\mathrm{CO}$ concentration decreased linearly with reduction time during the reduction of the powder material.

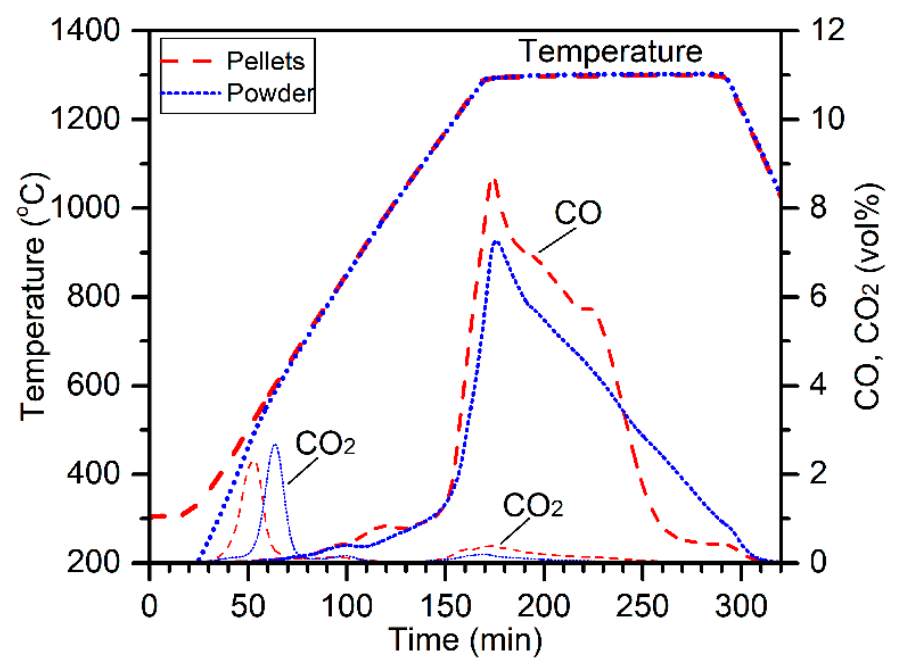

Figure 8. Temperature profiles and off-gas $\mathrm{CO}$ and $\mathrm{CO}_{2}$ concentrations for the tests using pellets and powder.

In the reduced products from both tests, considerable amounts of ferrochrome $\mathrm{M}_{7} \mathrm{C}_{3}$-type whiskers formed on the surfaces of the ferrochrome particles, as shown in Figure 9. These monocrystalline whiskers varied in size, were generally less than $10 \mu \mathrm{m}$ in thickness, and could grow up to $200 \mu \mathrm{m}$ long. Compared to the reduced products as shown in Figure 3 where only a few alloy whiskers were present, the formation of abundant alloy whiskers appears to have been induced by the presence of much higher amounts of siliceous gangue (i.e., clinochlore and phlogopite) in the 37-75 $\mu \mathrm{m}$ chromite fraction (Table 1). The reaction between the siliceous gangue and the $\mathrm{CaCl}_{2}$ contributed strongly to the formation of ferrochrome carbide whiskers, which will be discussed further in Section 3.6.

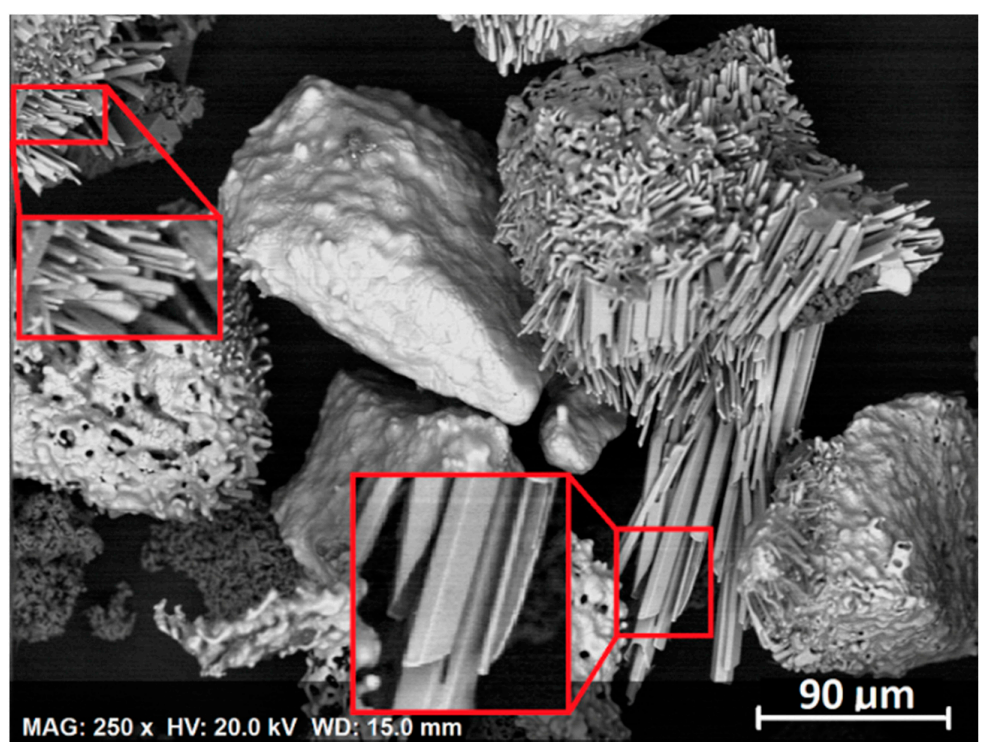

Figure 9. Ferrochrome alloy particles produced from the reduction of pellets containing 37-75 $\mu \mathrm{m}$ chromite, demonstrating the presence of monocrystalline ferrochrome carbide whiskers that had formed on the alloy surface. 


\subsection{Chromite Reduction by Petroleum Coke}

Pellets were prepared from a mixture of 75-105 $\mu \mathrm{m}$ chromite fraction, $75-105 \mu \mathrm{m}$ petroleum coke (22 wt \% of chromite), and finely ground $\mathrm{CaCl}_{2}$ (30 wt \% of chromite). A large sample of $178 \mathrm{~g}$ pellets was heated in the electric tube furnace with an Ar flow of $500 \mathrm{~mL} / \mathrm{min}$ at $1300{ }^{\circ} \mathrm{C}$ for $3 \mathrm{~h}$. Because of a much larger sample size used in this test, much higher amounts of $\mathrm{CO}$ and $\mathrm{CO}_{2}$ were produced, as indicated in Figure 10. Due to the extremely endothermic nature of the carbothermic chromite reduction, the actual temperature within the material bed was probably appreciably lower than that of the furnace temperature considering the much larger sample size used. Therefore, a comparatively longer time was required to reach near-complete reduction. Figure 11 illustrates the cross-section (a) and surface morphology (b) of the reduced product. Spherical ferrochrome alloy particles were produced, which resembled the spherical shape of the petroleum coke particles used in the study (c).

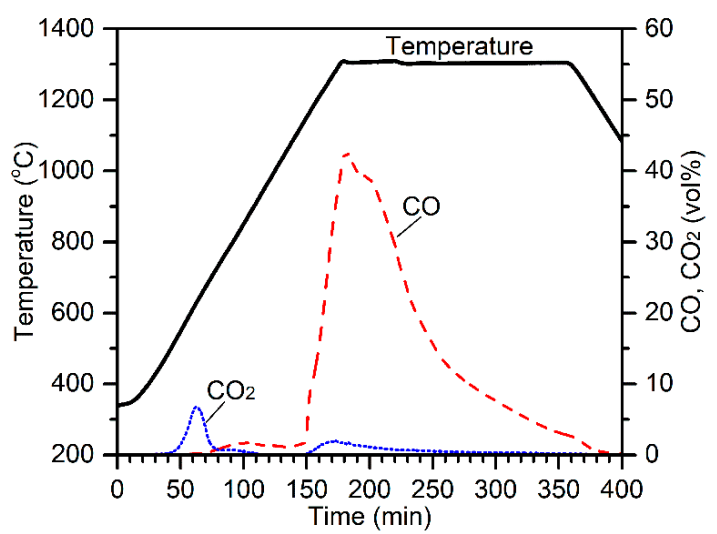

Figure 10. Temperature profiles and off-gas $\mathrm{CO}$ and $\mathrm{CO}_{2}$ concentrations for the test using petroleum coke as the reductant.
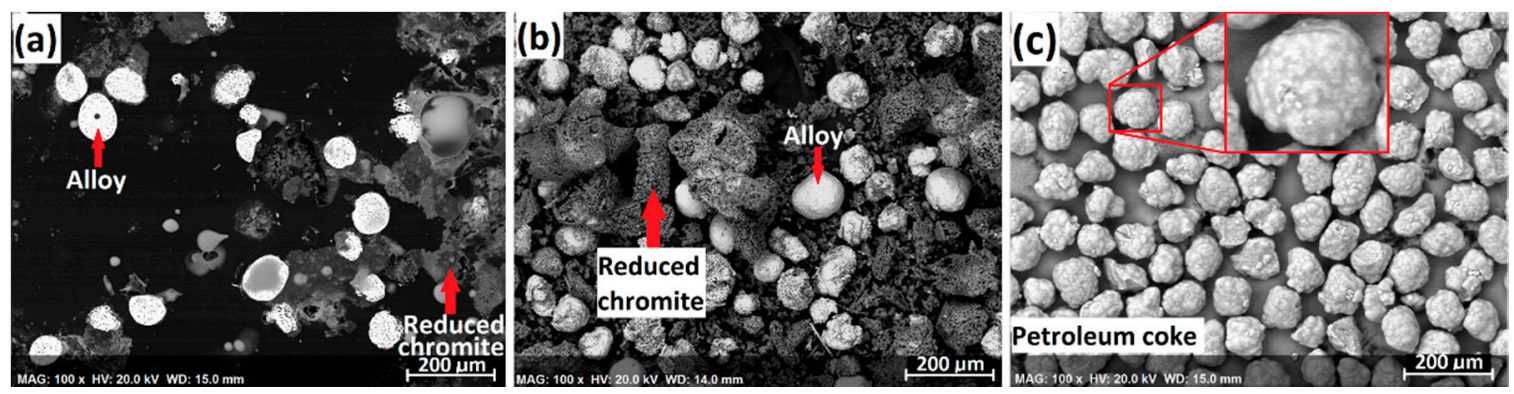

Figure 11. Cross-section (a), surface morphology (b) of the product from chromite reduction, and (c) the petroleum coke used for reduction.

\subsection{Morphologies of Ferrochrome}

Because of the presence of $\mathrm{CaCl}_{2}$, metallization mostly took place on the carbonaceous reductant particles. The sizes and shapes of the ferrochrome alloy particles were therefore largely determined by the starting reductant. Figure 12 illustrates the morphological variation of the ferrochrome alloy particles by using charcoal $(\mathrm{a}-\mathrm{c})$ and petroleum coke $(\mathrm{d}-\mathrm{f})$ as the reductants.

The most common morphology of the ferrochrome particles produced from reduction by charcoal is represented by Figure 12a as polycrystalline particles with/without pores. In the enlarged section, the darker polygon-shaped crystals are $\mathrm{Cr}$-rich $\mathrm{M}_{7} \mathrm{C}_{3}$-type carbide, while the lighter secondary phase is an Fe-rich alloy solid solution. The presence/absence of this secondary phase was probably dependent on the Cr:Fe ratio, as well as the availability of carbon in the alloy/carbon particle. As discussed, significant amounts of ferrochrome carbide $M_{7} C_{3}$ whiskers would form/grow on 
the alloy particles when charcoal was used to reduce chromite containing high proportions of siliceous gangue (e.g., 37-75 $\mu \mathrm{m}$ chromite fraction). Most monocrystalline whiskers exhibited hollow crystals with hexagonal outlines of varying length, missing one or more edges depending on the growth stage, as shown in Figure 12c. It can be seen from this figure that the growth of the whisker started from the formation of an $\mathrm{M}_{7} \mathrm{C}_{3}$ finger on the alloy particle surface, which further grew in length to form monocrystalline rod-shaped crystals. Subsequent 2-dimensional growth resulted in the formation of a plane, followed by 3-dimensional growth forming multiple edges of a hexagon. Solid hexagonal carbide whiskers, such as the ones in Figure 12b, were not commonly found. The growth of such hexagonal-shaped whiskers was because the $\mathrm{M}_{7} \mathrm{C}_{3}$-type carbide has a hexagonal crystalline lattice [28]. The hexagonal hollow $\mathrm{M}_{7} \mathrm{C}_{3}$ crystals were also observed in other studies $[29,30]$.

Reduction by petroleum coke produced relatively spherical ferrochrome alloy particles of varying porosity (Figure 12d-f), although the highly porous particles seen in Figure $12 \mathrm{f}$ were not common. The particles were polycrystalline $\mathrm{M}_{7} \mathrm{C}_{3}$ in the presence $(\mathrm{d})$ or absence (e) of the secondary Fe-rich alloy.
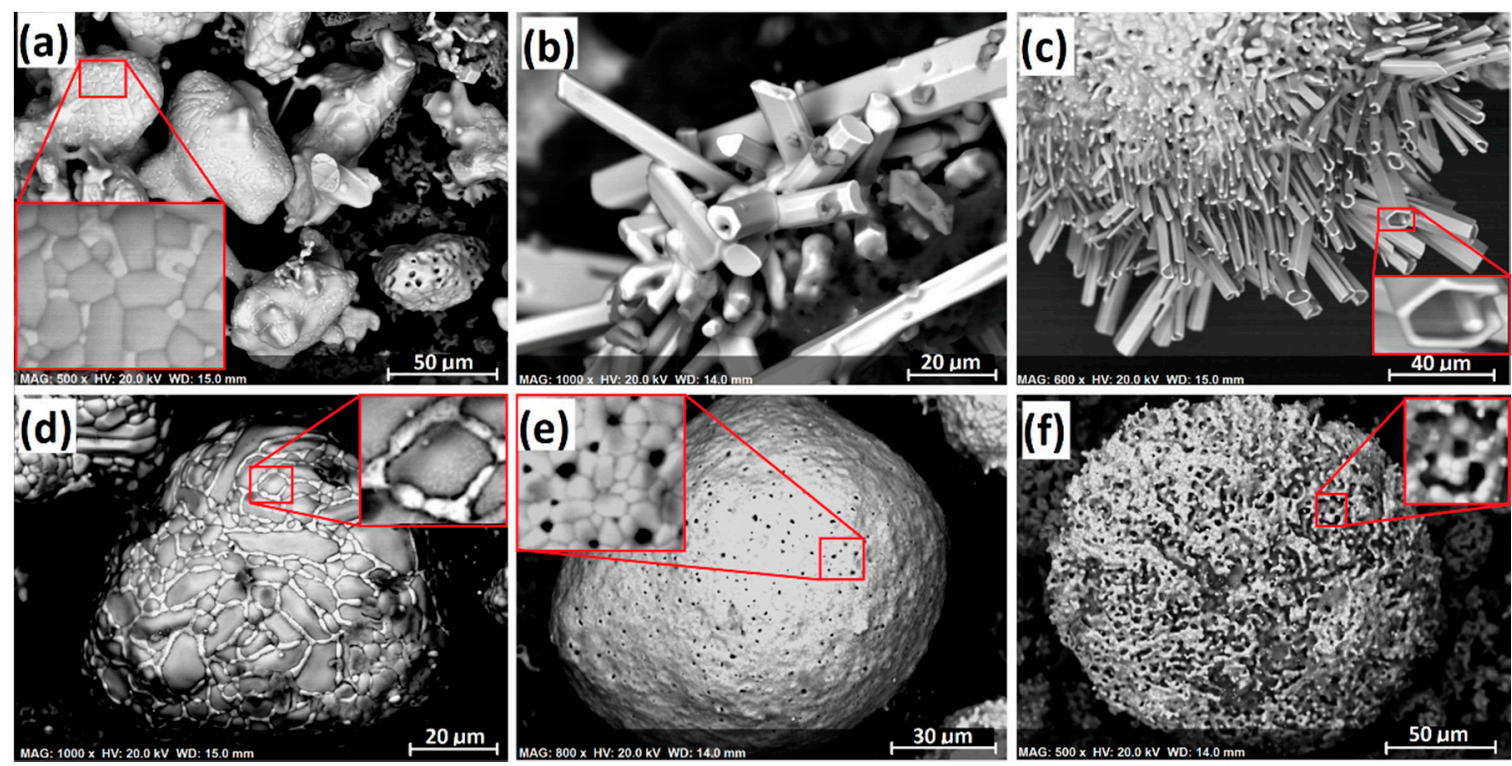

Figure 12. Various morphologies of the ferrochrome particles produced from reduction by charcoal $(\mathbf{a}-\mathbf{c})$ and petroleum coke $(\mathbf{d}-\mathbf{f})$.

\subsection{Segregation Reduction Mechanism}

To investigate the carbothermic segregation reduction mechanism of chromite in the presence of $\mathrm{CaCl}_{2}$, the possible reactions between the chromite ore and the $\mathrm{CaCl}_{2}$ were studied by the TG-DSC-MS test. The 75-105 $\mu \mathrm{m}$ chromite fraction was mixed with $30 \mathrm{wt} \%$ ground $\mathrm{CaCl}_{2}$ without the addition of any carbonaceous reductant. Approximately $70 \mathrm{mg}$ of the mixture was taken and heated to $1300{ }^{\circ} \mathrm{C}$ in $\mathrm{Ar}$ at $20^{\circ} \mathrm{C} / \mathrm{min}$ and held for $3 \mathrm{~h}$ before cooling to room temperature (Figure 13). As seen, two endotherms took place at about $150{ }^{\circ} \mathrm{C}$ and $250{ }^{\circ} \mathrm{C}$, corresponding to two $\mathrm{H}_{2} \mathrm{O}$ peaks and a mass loss. These two endotherms resulted from the thermal dehydration of $\mathrm{CaCl}_{2} \cdot x \mathrm{H}_{2} \mathrm{O}(x \approx 0.3)$. The slight hydration of $\mathrm{CaCl}_{2}$ was due to the absorption of moisture during sample preparation. The formation of $\mathrm{CO}_{2}$ at about $580{ }^{\circ} \mathrm{C}$ was from the thermal decomposition of magnesite, which was also observed in the furnace tests (e.g., Figure 2). Melting of $\mathrm{CaCl}_{2}$ took place at about $756{ }^{\circ} \mathrm{C}$, which is marked by the presence of the third endotherm. Thermal dehydration of clinochlore and phlogopite started at about $500{ }^{\circ} \mathrm{C}$ and continued until the temperature reached about $1280{ }^{\circ} \mathrm{C}$, which is represented by the continuous mass loss and evolution of gaseous $\mathrm{H}_{2} \mathrm{O}$. Mass loss continued at the isothermal temperature of $1300^{\circ} \mathrm{C}$, which could possibly be from the continuous vaporization of the molten $\mathrm{CaCl}_{2}$. XRD analysis of the sample collected from this test suggests the presence of chromite and wadalite 
$\left(\mathrm{Ca}_{6} \mathrm{Al}_{5} \mathrm{Si}_{2} \mathrm{O}_{16} \mathrm{Cl}_{3}\right)$ as the two dominant species. Morphology of the wadalite in the sample as shown in Figure 14 suggests that it was molten at $1300{ }^{\circ} \mathrm{C}$. Dissolution of the adjacent chromite particles by the molten wadalite resulted in its disintegration, forming discrete chromite particles disseminated in the molten wadalite phase, such as particle $\boldsymbol{a}$. Based on EPMA analysis as shown in Figure 14, the composition of the chromite particle can be represented as $\left(\mathrm{Mg}_{0.8} \mathrm{Fe}_{0.2}\right)\left(\mathrm{Cr}_{1.4} \mathrm{Al}_{0.5} \mathrm{Fe}_{0.1}\right) \mathrm{O}_{4}$ with an average $\mathrm{CaO}$ concentration of $0.8 \mathrm{wt} \%$. Chromite containing as much as $4.2 \mathrm{wt} \% \mathrm{CaO}$ was identified by EPMA. In comparison, the chromite phase in the pristine ore sample $\left(\mathrm{Fe}_{0.5} \mathrm{Mg}_{0.5}\right)\left(\mathrm{Cr}_{1.4} \mathrm{Al}_{0.5} \mathrm{Fe}_{0.1}\right) \mathrm{O}_{4}$ contained only trace amounts of $\mathrm{CaO}$, which is about three orders of magnitudes lower. The formation of wadalite and the Ca-bearing chromite is suggested to be due to sequential reactions involving $\mathrm{CaCl}_{2}$, which can be represented by Equation (7) and Figure 15. This was proposed based on the following analyses.

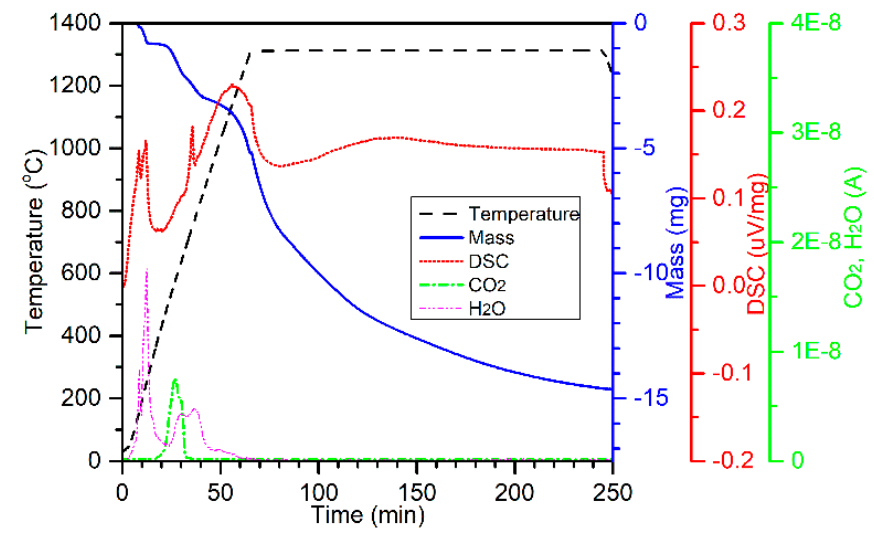

Figure 13. TG-DSC-MS test on the interaction between the chromite ore and $\mathrm{CaCl}_{2}$.
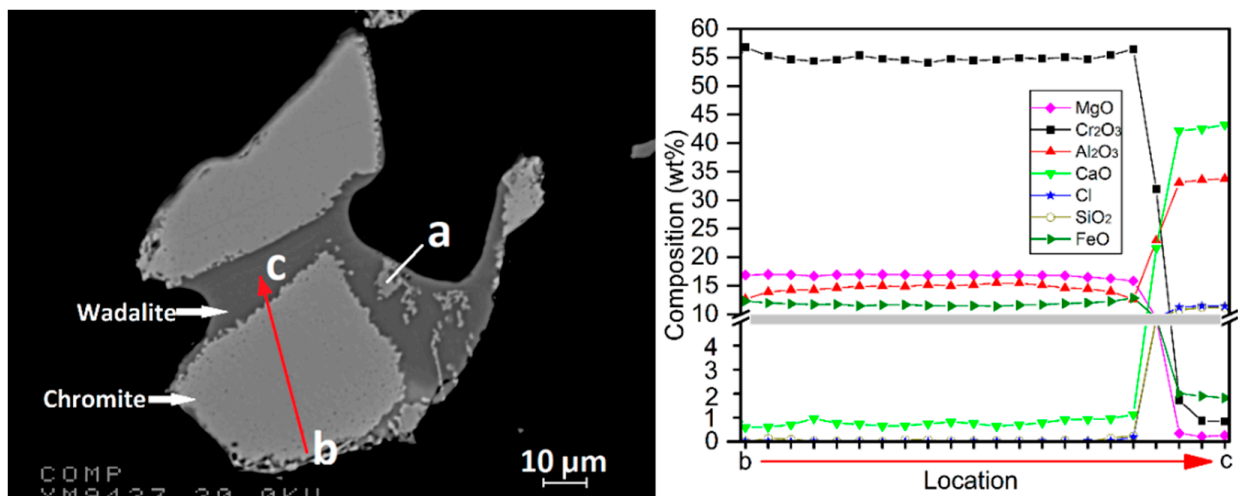

Figure 14. BSE image of the product from the TG-DSC-MS test showing the presence of wadalite and the electron probe microanalysis (EPMA) line scan along the arrow $\mathrm{b} \rightarrow \mathrm{c}$.

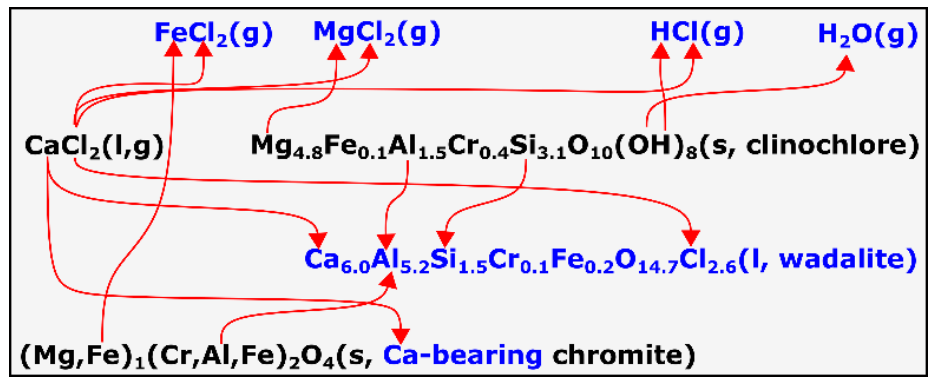

Figure 15. Illustration of the proposed interactions among $\mathrm{CaCl}_{2}$, clinochlore, and chromite. 
The average stoichiometry of the clinochlore in the chromite ore can be represented as $\mathrm{Mg}_{4.8} \mathrm{Fe}_{0.1} \mathrm{Al}_{1.5} \mathrm{Cr}_{0.4} \mathrm{Si}_{3.1} \mathrm{O}_{10}(\mathrm{OH})_{8}$ based on the EPMA analysis. It was reported by Villieras et al. [31] that the thermal dehydroxylation of clinochlore leads to the formation of a heterogeneous structure with the presence of micropores. This formation of micropores would have accelerated its reaction with molten $\mathrm{CaCl}_{2}$. The wadalite phase formed was highly aluminous with an Al/Si molar ratio of 2.5, whereas it was only 0.49 in the clinochlore, suggesting that $\mathrm{Al}_{2} \mathrm{O}_{3}$ was produced by the dissolution of chromite. This is evidenced by the gradual disintegration of chromite in the presence of the molten wadalite (Figure 14). It was further confirmed by the EPMA line scan along the arrow $\boldsymbol{b} \rightarrow \boldsymbol{c}$ as shown in Figure 14 because the incongruent dissolution of chromite into the wadalite phase led to the decreasing $\mathrm{Al}_{2} \mathrm{O}_{3}$ concentration gradient from the center of the chromite particle to the boundary between chromite and wadalite. Evidenced by the drastic decrease in $\mathrm{Fe}^{2+}$ of the chromite phase $\left(\mathrm{Mg}_{0.8} \mathrm{Fe}_{0.2}\right)\left(\mathrm{Cr}_{1.4} \mathrm{Al}_{0.5} \mathrm{Fe}_{0.1}\right) \mathrm{O}_{4}$ after the test when comparing to that of the pristine chromite $\left(\mathrm{Fe}_{0.5} \mathrm{Mg}_{0.5}\right)\left(\mathrm{Cr}_{1.4} \mathrm{Al}_{0.5} \mathrm{Fe}_{0.1}\right) \mathrm{O}_{4}$, the removal of octahedral $\mathrm{FeO}$ became apparent, which was probably due to chloridization forming volatile $\mathrm{FeCl}_{2}$. In addition, other chlorides were likely to have formed, such as gaseous $\mathrm{MgCl}_{2}$, from chloridization of $\mathrm{Mg}^{2+}$ in the clinochlore. Formation of $\mathrm{HCl}$ was also likely in the presence of gaseous $\mathrm{H}_{2} \mathrm{O}$, which was released from the dehydroxylation of clinochlore. Evolution of all the gas species that appear in Figure 15 and their subsequent removal by the Ar flow resulted in the continuous mass loss, which is shown in Figure 13. However, this does not exclude the possible formation of other chlorides such as $\mathrm{CrCl}_{2}, \mathrm{CrCl}_{3}$, and $\mathrm{AlCl}_{3}$, etc.

$$
\mathrm{CaCl}_{2}(\mathrm{l})+\text { Clinochlore}(\mathrm{s})+\text { Chromite }(\mathrm{s}) \rightarrow \text { Wadalite }(\mathrm{l})+\text { Ca-bearing chromite }(\mathrm{s})+\text { chlorides }(\mathrm{g})
$$

Although wadalite was the main product of the interactions between $\mathrm{CaCl}_{2}$ and the chromite ore, other species were also identified, such as $\mathrm{Ca}_{2} \mathrm{SiO}_{4}$ and a Cl-bearing calcium silicate, which are shown in Figure 16. Discrete Ca-bearing chromite particles were produced from the interactions (Figure 15) and were spread in the likely molten silicate at $1300{ }^{\circ} \mathrm{C}$, which subsequently produced wadalite, $\mathrm{Ca}_{2} \mathrm{SiO}_{4}$, and the $\mathrm{Cl}$-bearing calcium silicate upon solidification.
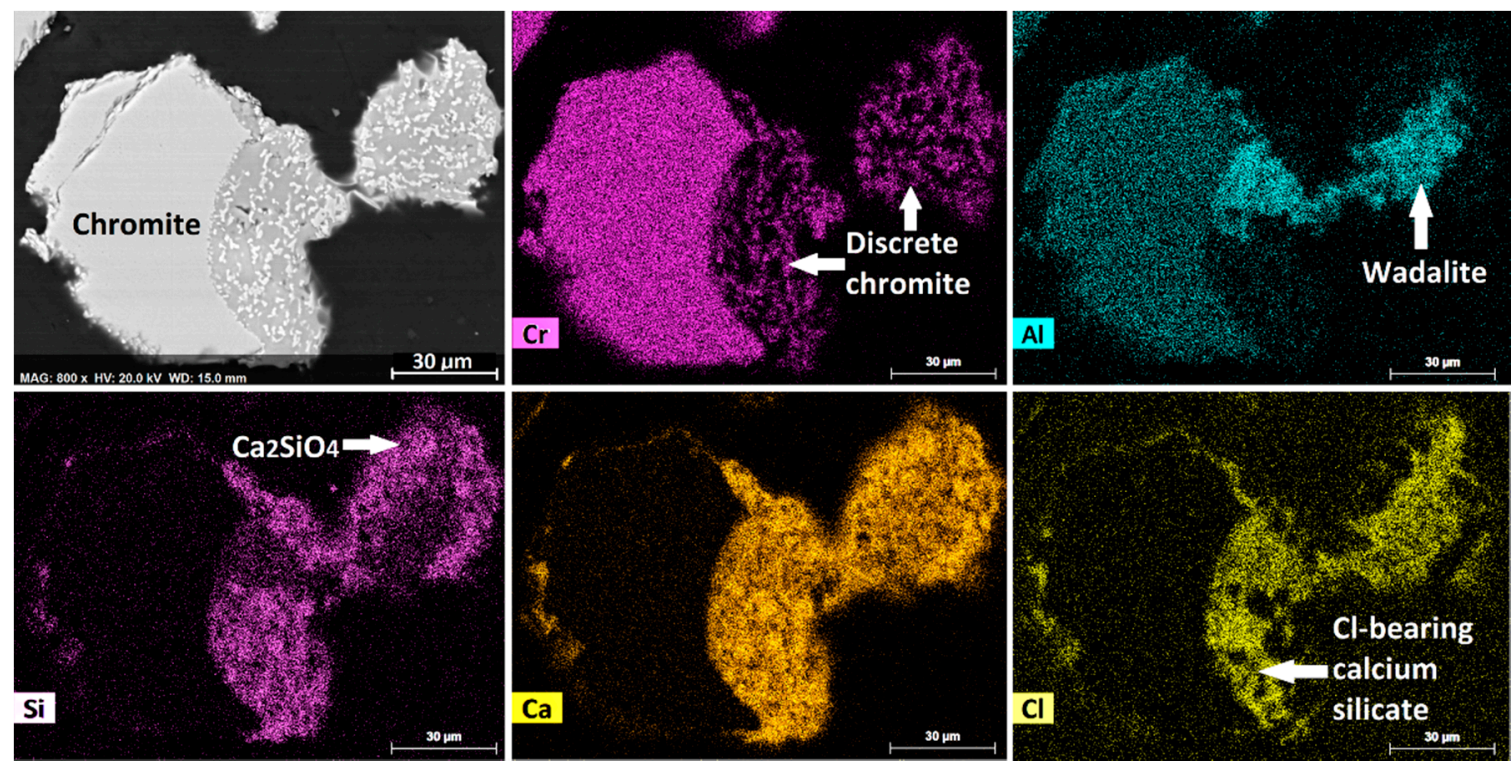

Figure 16. BSE and elemental mapping images illustrating the presence of residual chromite particles disseminated in the secondary silicates (i.e., wadalite, $\mathrm{Ca}_{2} \mathrm{SiO}_{4}$, and a Cl-bearing calcium silicate).

Another TG-DSC-MS test was performed on 75-105 $\mu \mathrm{m}$ chromite mixed with $30 \mathrm{wt} \% \mathrm{CaCl}_{2}$ and $25 \mathrm{wt} \%$ graphite powder $(25-37 \mu \mathrm{m})$. A partial reduction was achieved by heating at $20{ }^{\circ} \mathrm{C} / \mathrm{min}$ to $1300^{\circ} \mathrm{C}$, followed by immediate cooling to room temperature. EPMA analysis of the partially reduced 
sample showed the formation of ferrochrome alloys on carbon particles with a $\mathrm{Cr} / \mathrm{Fe}$ ratio of about 1.4, which is lower than that of the pristine chromite (i.e., $\mathrm{Cr} / \mathrm{Fe}=2.0$ ). Figure 17 illustrates the BSE and elemental mapping images of a partially reduced chromite particle. The residual chromite core exhibited an Fe concentration gradient, indicating the preferential chloridization of the Fe species. The oxide rim surrounding the chromite core was highly porous and impregnated with chlorides, as shown by the $\mathrm{Cl}$ mapping. Consequently, this ubiquitous presence of the molten and/or gaseous $\mathrm{CaCl}_{2}$ in the space between the chromite and carbon particles, and especially inside the porous chromite rim, significantly decreased the gaseous reduction potential, thereby minimizing the metallization within the chromite particles.
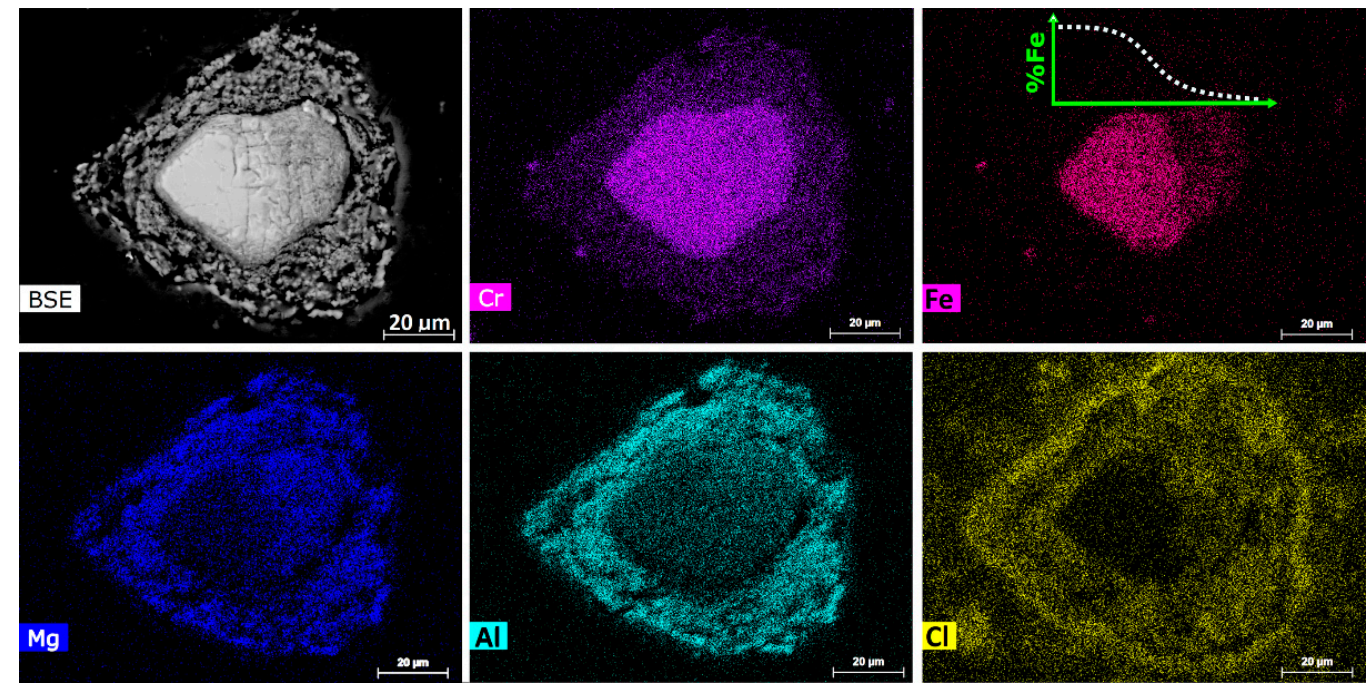

Figure 17. BSE and elemental mapping of a partially reduced chromite.

To better understand the role of $\mathrm{CaCl}_{2}$ in the segregation reduction of chromite, a phase stability diagram of the $\mathrm{Cr}-\mathrm{Fe}-\mathrm{Ca}-\mathrm{Cl}-\mathrm{O}$ system at $1300{ }^{\circ} \mathrm{C}$ was plotted using FactSage [17] as a function of the partial pressures of $\mathrm{O}_{2}$ and $\mathrm{Cl}_{2}$, which is shown in Figure 18. Two horizontal red dashed lines represent the equilibrium $\mathrm{O}_{2}$ potentials that can be achieved from carbothermic reduction by $\mathrm{CO}$ and $\mathrm{C}$, respectively. With the presence of solid carbon, carbothermic reduction of chromite can take place via two possible mechanisms. The first mechanism is the direct reduction of chromite by solid carbon, which takes place in localized areas where the chromite and carbon particles are in physical contact. The second mechanism is the indirect gaseous reduction of chromite with $\mathrm{CO}$ as the direct reducing agent, coupled with the Boudouard reaction, which is represented by Equations (8) and (9), respectively. The Boudouard reaction provides the driving force for the continuation of the reaction Equation (8) by constantly removing the gaseous product (i.e., $\mathrm{CO}_{2}$ ) and re-generating the gaseous reductant (i.e., CO). Apparently, the direct reduction mechanism involves solid diffusion, requiring physical contact between the chromite and carbon particles, while the indirect reduction mechanism necessitates counterflow and transport of $\mathrm{CO}$ and $\mathrm{CO}_{2}$ in the gas phase. As schematically illustrated in Figure 18 on the right-hand side, in the segregation reduction system with the presence of molten and/or gaseous $\mathrm{CaCl}_{2}$ between the chromite and carbon particles, both the direct and indirect reduction can be hindered by reducing the physical contact between chromite and carbon particles, and by slowing the counter flow of $\mathrm{CO}$ and $\mathrm{CO}_{2}$. Due to the introduction of this kinetic limitation, variation in localized thermodynamic equilibriums is promoted. In other words, the local $\mathrm{O}_{2}$ potential inside or immediately surrounding the carbon particles is closer to that of the C-CO equilibrium (i.e., $\sim 1 \times 10^{-16.6} \mathrm{~atm}$ ), while the local $\mathrm{O}_{2}$ potential inside the chromite particles is comparatively much higher and could be close to that of the $\mathrm{CO}-\mathrm{CO}_{2}$ equilibrium (i.e., $\sim 1 \times 10^{-9.8} \mathrm{~atm}$ ). This restricts the formation of ferrochrome to the carbon particles, because it requires an $\mathrm{O}_{2}$ potential of lower 
than $1 \times 10^{-16} \mathrm{~atm}$, as shown in Figure 18. As indicated by the arrow in the phase stability diagram, the chromite would be progressively exposed to a lowering $\mathrm{O}_{2}$ potential with continuation of the carbothermic reduction, which in turn promotes the chloridization of Fe and $\mathrm{Cr}$ species forming $\mathrm{FeCl}_{2}$ and $\mathrm{CrCl}_{2}$. In addition, chloridization of $\mathrm{Cr}$ species requires a lower $\mathrm{O}_{2}$ potential than that for Fe species, which explains the preferential chloridization of Fe from the chromite core as appears in Figure 17. The presence of molten and/or gaseous $\mathrm{CaCl}_{2}$ in the sample mixture maintained the chloridizing atmosphere that allowed the formation and transportation of volatile chlorides of Fe and $\mathrm{Cr}$, before being reduced on the carbon particles forming ferrochrome alloy.

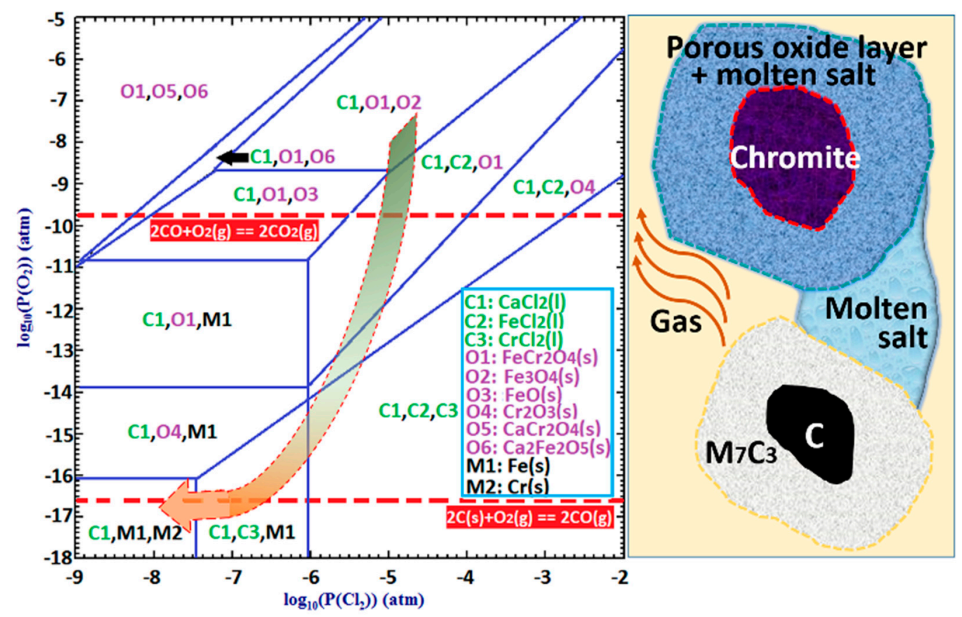

Figure 18. Phase stability diagram of the $\mathrm{Cr}-\mathrm{Fe}-\mathrm{Ca}-\mathrm{Cl}-\mathrm{O}$ system at $1300{ }^{\circ} \mathrm{C}$ calculated using FactSage [17], and the schematic illustration of the segregation reduction of chromite in the presence of $\mathrm{CaCl}_{2}$.

$$
\begin{gathered}
4 \mathrm{CO}+\mathrm{FeCr}_{2} \mathrm{O}_{4}=\mathrm{FeCr}_{2} \text { (alloy) }+4 \mathrm{CO}_{2} \\
\mathrm{C}+\mathrm{CO}_{2}=2 \mathrm{CO}
\end{gathered}
$$

Using the phase stability diagram in Figure 18, the formation of discrete micron-sized Fe-rich ferrochrome particles in some chromite particles as shown in Figures 4 and 5 can also be explained. Due to the heterogeneous nature of the sample mixture, $\mathrm{CaCl}_{2}$ could be distributed unevenly. Therefore, some chromite cores were exposed to a lower chloridizing atmosphere (e.g., $\mathrm{P}_{\mathrm{Cl} 2}<1 \times 10^{-6}$ atm) because of the deficiency of $\mathrm{CaCl}_{2}$ in their porous rim. When the $\mathrm{O}_{2}$ potential inside the chromite particles was lower than $1 \times 10^{-10.9}$ atm (Figure 18), preferential metallization of Fe took place, forming the discrete Fe-rich ferrochrome particles in the core region of the chromite particles.

The formation mechanism of the ferrochrome carbide whiskers was also investigated. Because the whisker formation only took place when charcoal was used, and it was not observed when petroleum coke was used as the carbonaceous reductant, reactivity of the charcoal must have played a significant role. Figure 19 exhibits (a) the surface morphology of the charcoal used for reduction, (b) the calcined charcoal after heating at $1300{ }^{\circ} \mathrm{C}$ for $10 \mathrm{~min}$ in an argon atmosphere, and (c) the residual charcoal in the segregation reduction product. As seen, significant amounts of micropores were formed in the calcine charcoal, possibly due to the removal of volatiles. The porosity became much higher during segregation reduction, indicated by Figure 19c. In addition, whisker formation was significantly promoted in the presence of higher amounts of siliceous gangue (e.g., clinochlore), suggesting the involvement of clinochlore (Equation (7) and Figure 15). Therefore, the formation mechanism of ferrochrome whiskers is tentatively suggested as follow. A significant amount of $\mathrm{H}_{2} \mathrm{O}$, which was produced from thermal dehydroxylation of clinochlore and phlogopite, was retained in the porous charcoal particles. It was subsequently reduced by charcoal to form $\mathrm{H}_{2}$, represented by Equation (10). Based on thermodynamic analysis, gaseous $\mathrm{MgCl}_{2}$ and $\mathrm{HCl}$ generated from the interaction among $\mathrm{CaCl}_{2}$, clinochlore, and chromite (Figure 15) are strong chloridizing agents (Equations (11) and (12)) 
Due to the high surface area of the porous charcoal, a stronger reducing potential (i.e., lower $\mathrm{P}_{\mathrm{O} 2}$ ) was generally present in the gas phase resulting from the accelerated Boudouard reaction (Equation (9)) and the reduction of $\mathrm{H}_{2} \mathrm{O}$ (Equation (10)). Therefore, not only was metallization by $\mathrm{H}_{2}$ reduction (Equation (13)) taking place on the carbon particle surface but its growth into the space further away from the carbon particles was being promoted, resulting in whisker formation and growth. The combination of these conditions was essential for the formation and growth of the ferrochrome whiskers. Continuous segregation reduction was realized from the complete cycle of $\mathrm{H}_{2}$ re-generation (Equation (10)), metallization and $\mathrm{HCl}$ re-generation (Equation (13)), and chloridization (Equation (12)). The loss of gaseous $\mathrm{H}_{2}, \mathrm{H}_{2} \mathrm{O}$, and $\mathrm{HCl}$ into the Ar flow can be significantly reduced by increasing the sample size. A large-scale electric tube furnace test was therefore performed with the same Ar flow of $500 \mathrm{~mL} / \mathrm{min}$ using a mixture of $150 \mathrm{~g}$ chromite $(37-75 \mu \mathrm{m}), 33 \mathrm{~g}$ charcoal $(105-180 \mu \mathrm{m})$, and $45 \mathrm{~g}$ ground $\mathrm{CaCl}_{2}$, heated at $1300{ }^{\circ} \mathrm{C}$ for $3 \mathrm{~h}$. The loss of those reactive gas species into the Ar flow was significantly reduced because of a much larger sample thickness. Much higher amounts of carbide whiskers were formed in the product, which is shown in Figure 20. In addition, long carbide whiskers ( $\sim 200 \mu \mathrm{m}$ in length) grew on the inner wall of the alumina crucible above the material bed during segregation reduction, as seen in Figure 20c. The results from this large-scale test are in good agreement with the proposed mechanism for whisker formation.
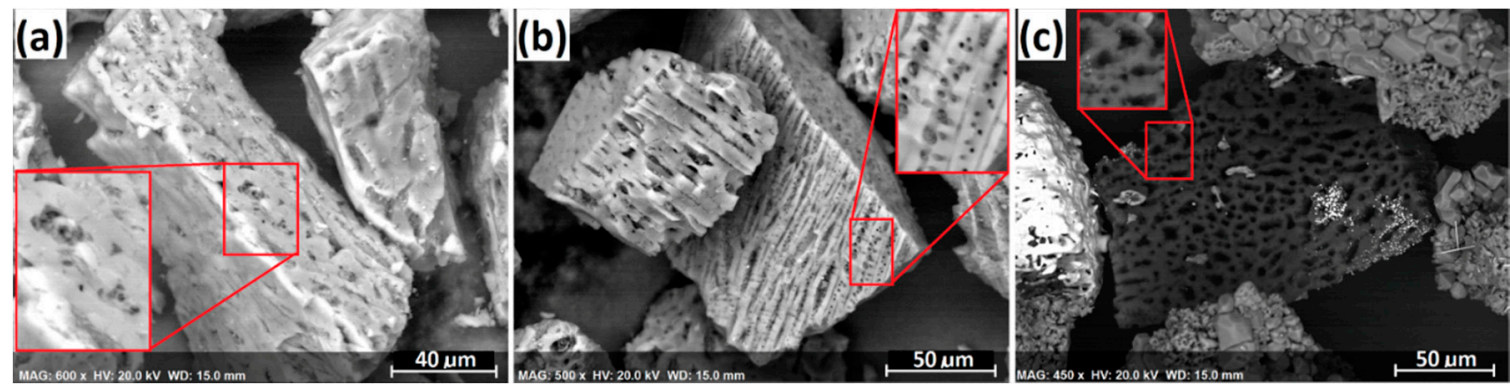

Figure 19. (a) Charcoal; (b) calcined charcoal showing the presence of micropores; and (c) residual charcoal in the segregation reduction product.

$$
\begin{gathered}
\mathrm{H}_{2} \mathrm{O}+\mathrm{C}=\mathrm{H}_{2}+\mathrm{CO} \\
\mathrm{MgCl}_{2}+\mathrm{MeO}=\mathrm{MgO}+\mathrm{MeCl}_{2}(\mathrm{Me}=\mathrm{Fe} \text { or } \mathrm{Cr}) \\
2 \mathrm{HCl}+\mathrm{MeO}=\mathrm{MeCl}_{2}+\mathrm{H}_{2} \mathrm{O} \\
\mathrm{MeCl}_{2}+\mathrm{H}_{2}=\mathrm{Me}+2 \mathrm{HCl}
\end{gathered}
$$
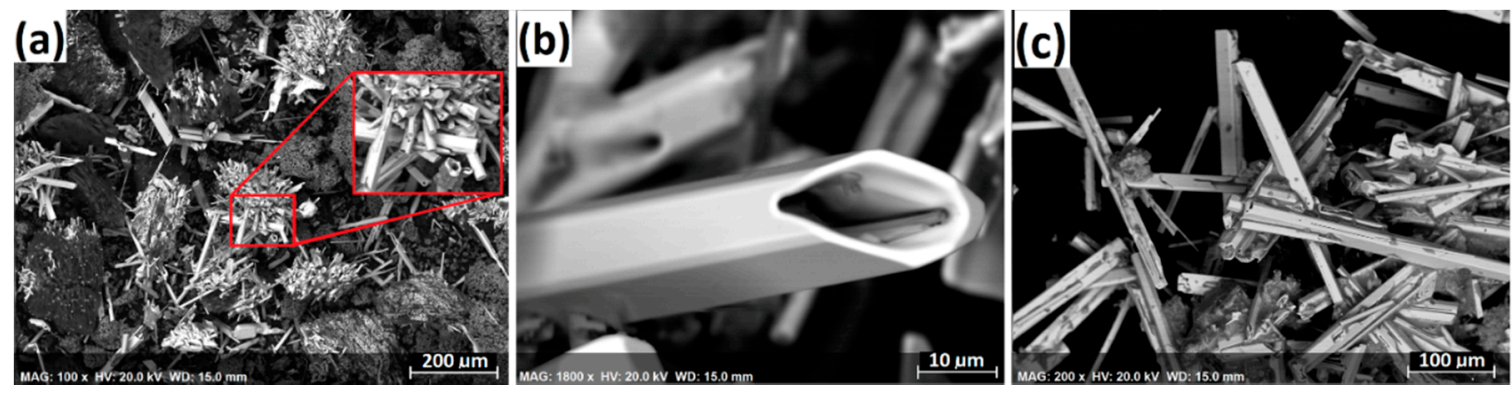

Figure 20. (a) Formation of ferrochrome mostly as $M_{7} C_{3}$ carbide whiskers in the reduced product from the large-scale segregation reduction of 37-75 $\mu \mathrm{m}$ chromite; in which (b) hollow hexagonal carbide whiskers were formed; and (c) ferrochrome carbide whiskers averaging about $200 \mu \mathrm{m}$ in length have grown on the inner wall of the crucible during reduction. 
It should be noted that formation of the polycrystalline-type ferrochrome particles (e.g., Figure 12a) was less likely to have involved the hydrogen-bearing gases (i.e., $\mathrm{H}_{2} \mathrm{O}, \mathrm{H}_{2}$, and $\mathrm{HCl}$ ). This is suggested by the higher reduction rate achieved when 180-300 $\mu \mathrm{m}$ chromite was reduced as shown in Figure 2, and regular-shaped polycrystalline ferrochrome particles were formed (Figure 3b,d). Because this chromite fraction contained much less gangue (i.e., clinochlore and phlogopite) as shown in Table 1 , the contribution from the hydrogen-bearing gases was much less significant. This suggests the presence of another important segregation mechanism, which requires further investigation.

\section{Conclusions}

$\mathrm{CaCl}_{2}$-assisted segregation reduction of chromite in a wide particle size range of 37-300 $\mu \mathrm{m}$ was evaluated at $1300{ }^{\circ} \mathrm{C}$ using both charcoal and petroleum coke as the reductants. Results show that near-complete reduction generally took place within about $2 \mathrm{~h}$. The presence of $\mathrm{CaCl}_{2}$ was effective in segregating the $\mathrm{Cr}$ and $\mathrm{Fe}$ species from the chromite particles followed by metallization on the carbon particles, leaving behind the porous refractory particles composed of mainly $\mathrm{MgAl}_{2} \mathrm{O}_{4}$ and $\mathrm{MgO}$ phases. Both the chromite and carbon particles followed the shrinking-core model during the segregation reduction. The ferrochrome particles produced were generally polycrystalline $\mathrm{M}_{7} \mathrm{C}_{3}$-type carbide with/without the presence of a secondary Fe-rich alloy phase along the crystal boundaries. The size and shape of the ferrochrome particles were largely determined by that of the carbon particles.

Formation of $\mathrm{Cr}$-rich ferrochrome required an extremely low $\mathrm{O}_{2}$ potential (e.g., $<1 \times 10^{-16} \mathrm{~atm}$ at $1300{ }^{\circ} \mathrm{C}$ ), which took place restrictedly on the carbon particles in the presence of $\mathrm{CaCl}_{2}$. Because of the ubiquitous presence of the molten and/or gaseous $\mathrm{CaCl}_{2}$ in between the chromite and the carbon particles, and especially in the porous rim of the chromite particles during reduction, metallization within chromite particles was minimized likely because of a much higher local $\mathrm{O}_{2}$ potential. When there was less $\mathrm{CaCl}_{2}$ surrounding a particular chromite particle due to the uneven distribution, micron-sized discrete Fe-rich ferrochrome alloy particles could form inside this chromite particle close to its center. $\mathrm{CaCl}_{2}$ could react with the siliceous gangue (e.g., clinochlore) and the chromite, forming Ca-bearing chromite, wadalite, and gaseous chlorides such as $\mathrm{MgCl}_{2}, \mathrm{FeCl}_{2}$, and /or $\mathrm{HCl}$, etc. Monocrystalline hexagonal $\mathrm{M}_{7} \mathrm{C}_{3}$-type ferrochrome whiskers were formed only when charcoal was used to reduce chromite ore containing relatively high amounts of siliceous gangue. This was likely due to the generation and involvement of hydrogen-bearing gases (i.e., $\mathrm{H}_{2} \mathrm{O}, \mathrm{HCl}$, and $\mathrm{H}_{2}$ ) and possibly $\mathrm{MgCl}_{2}$. Combining with the highly reactive and porous nature of the charcoal, both the chloridization and metallization by $\mathrm{H}_{2}$ reduction were enhanced, which promoted the formation and growth of monocrystalline whiskers. However, the overall segregation reduction of chromite did not necessarily require the presence of siliceous gangue, nor did it involve the hydrogen-bearing gases. This indicates another segregation reduction mechanism, which requires further investigation.

In addition, as an integral part of this innovative $\mathrm{CaCl}_{2}$-assisted segregation reduction process for the direct production of ferrochrome, separation of the ferrochrome alloy particles from the unwanted gangue present in the reduced products necessitates further study. This can be achieved by conventional gravity or magnetic concentration techniques. Commercialization of this alternate process of ferrochrome production is promising as conventional furnaces such as a rotary kiln could be employed for this purpose. Compared to the conventional EAF smelting, this new direct reduction process offers significant potential for energy savings by employing a much lower reduction temperature. Furthermore, the $\mathrm{CaCl}_{2}$ in the reduced product could be recovered for re-use by simply water-leaching the product, thereby significantly reducing the operating costs.

Acknowledgments: The following contributions are acknowledged: Yves Thibault and Dominique Duguay for assisting with the EPMA analysis, and KWG Resources Inc. for providing the chromite ore samples. The study was funded by NRCan under the Rare Earth Elements and Chromite R\&D Program.

Author Contributions: Dawei Yu conceived and designed the experiments; Dawei Yu performed the experiments; Dawei Yu analyzed the data; Dawei Yu and Dogan Paktunc contributed reagents/materials/analysis tools; Dawei Yu 
and Dogan Paktunc wrote the paper. Dogan Paktunc as the principal investigator of the Chromite/Ferrochrome project conceptualized the broad project objectives.

Conflicts of Interest: The authors declare no conflict of interest.

\section{References}

1. Basson, J.; Daavittila, J. High Carbon Ferrochrome Technology. In Handbook of Ferroalloys: Theory and Technology; Gasik, M., Ed.; Butterworth-Heinemann Elsevier: Oxford, UK, 2013; pp. 317-363, ISBN 9780080977539.

2. Bragg, W.H. The structure of the spinel group of crystals. Lond. Edinb. Dublin Philos. Mag. J. Sci. 1915, 30, 305-315. [CrossRef]

3. Hill, R.J.; Craig, J.R.; Gibbs, G.V. Systematics of the spinel structure type. Phys. Chem. Miner. 1979, 4, 317-339. [CrossRef]

4. Johnson, J.; Reck, B.K.; Wang, T.; Graedel, T.E. The energy benefit of stainless steel recycling. Energy Policy 2008, 36, 181-192. [CrossRef]

5. Duong, H.V.; Johnston, R.F. Kinetics of solid state silica fluxed reduction of chromite with coal. Ironmak. Steelmak. 2000, 27, 202-206. [CrossRef]

6. Kekkonen, M.; Holappa, L.; Niemela, P. Kinetic study on smelting reduction of chromite ore. In Proceedings of the Infacon IX-The Ninth International Ferroalloys Congress, Quebec City, QC, Canada, 3-6 June 2001; pp. 157-165.

7. Soykan, O.; Eric, R.H.; King, R.P. The reduction mechanism of a natural chromite at $1416{ }^{\circ}$ C. Metall. Trans. $B$ 1991, 22B, 53-63. [CrossRef]

8. Weber, P.; Eric, R.H. The reduction mechanism of chromite in the presence of a silica flux. Metall. Trans. $B$ 1992, 24, 987-995. [CrossRef]

9. Weber, P.; Eric, R.H. Solid-state fluxed reduction of LG-6 chromite from the Bushveld complex. In Proceedings of the INFACON 6-6th International Ferroalloys Congress, Cape Town, South Africa, 8-11 March 1992; pp. 71-77.

10. Yu, D.; Paktunc, D. Kinetics and Mechanisms of the Carbothermic Reduction of Chromite in the Presence of Nickel. J. Therm. Anal. Calorim. 2018, 1-12. [CrossRef]

11. Hussein, M.K.; El-Barawi, K. Study of the chlorination and beneficiation of Egyptian chromite ores. Trans. Inst. Min. Metall. Sect. C 1971, 80,7-11.

12. Hussein, M.K.; Winterhager, H.; Kammel, R. Chlorination behavior of the main oxide components chromite ores. Trans. Inst. Min. Metall. Sect. C 1974, 83, 154-160.

13. Kanari, N.; Gaballah, I.; Allain, E. A study of chromite carbochlorination kinetics. Metall. Mater. Trans. B 1999, 30B, 577-587. [CrossRef]

14. Kanari, N.; Allain, E.; Joussemet, R.; Mochon, J.; Ruiz-Bustinza, I.; Gaballah, I. An overview study of chlorination reactions applied to the primary extraction and recycling of metals and to the synthesis of new reagents. Thermochim. Acta 2009, 495, 42-50. [CrossRef]

15. Shen, S.B.; Bergeron, M.; Richer-Lafleche, M. Effect of sodium chloride on the selective removal of iron from chromite by carbochlorination. Int. J. Miner. Process. 2009, 91, 74-80. [CrossRef]

16. Natari, N.; Gaballah, I.; Allain, E. Kinetics of oxychlorination of chromite Part I. Effect of temperature. Thermochim. Acta 2001, 371, 143-154.

17. Bale, C.W.; Belisle, E.; Chartrand, P.; Decterov, S.A.; Eriksson, G.; Gheribi, A.E.; Hack, K.; Jung, I.H.; Yang, Y.B.; Melancon, J.; et al. FactSage Thermochemical Software and Database, 2010-2016. Calphad 2016, 54, 35-53. [CrossRef]

18. Moulden, J.C.; Taplin, B. Improvements in or Relating to the Heat Treatment of Oxidized Copper Ores. British Patent 250991, 1924.

19. Brittan, M.I. Kinetics of copper segregation by the Torco process. J. S. Afr. Inst. Min. Metall. 1970, $278-289$.

20. Bhattacharya, M. Reaction mechanism and thermodynamics of segregation roasting of iron oxide. Int. J. Miner. Process. Extr. Metall. 2016, 1, 64-69.

21. Hernandez, V.; Peake, K.; Dalvi, A.; Brown, R.; Olurin, J.; O’Farrell, T.; Zhou, M.; Liu, B.; Cameron, I. Process development of a new DRI technology for Oolitic iron ores. In AISTech Proceedings; Association for Iron \& Steel Technology: Pittsburgh, PA, USA, 2013; pp. 519-526. 
22. Kwatara, M.; Tayabally, J.; Peek, E.; Schonewille, R. Segregation roasting of a saprolitic ore-An experimental investigation. In EPD Congress 2011; Monteiro, S.N., Verhulst, D.E., Anyalebechi, P.N., Pomykala, J.A., Eds.; John Wiley \& Sons, Inc.: Hoboken, NJ, USA, 2011.

23. Liu, W.; Li, X.; Hu, Q.; Wang, Z.; Gu, K.; Li, J.; Zhang, L. Pretreatment study on chloridizing segregation and magnetic separation of low-grade nickel laterites. Trans. Nonferr. Met. Soc. China 2010, 20, s82-s86. [CrossRef]

24. Mehrotra, S.P.; Srinivasan, V. Extraction of nickel from an Indian laterite by segregation roasting. Trans. Inst. Min. Metall. 1994, 103, C97-C104.

25. Okamoto, K.; Ueda, Y.; Noguchi, F. Mechanism of nickel segregation from gernierite ores. J. Min. Metall. Inst. Jpn. 1971, 87, 103-108.

26. Zhou, S.; Wei, Y.; Li, B.; Wang, H.; Ma, B.; Wang, C. Chloridization and reduction roasting of high-magnesium low-nickel oxide ore followed by magnetic separation to enrich ferronickel concentrate. Metall. Mater. Trans. $B$ 2016, 47B, 145-153. [CrossRef]

27. Zhou, S.; Wei, Y.; Li, B.; Wang, H.; Ma, B.; Wang, C. Mechanism of sodium chloride in promoting reduction of high-magnesium low-nickel oxide ore. Sci. Rep. 2016, 6, 29061. [CrossRef] [PubMed]

28. Bolgar, A.S.; Turchanin, A.G.; Fesenko, V.V. Thermodynamic Properties of Carbides; Naukova Dumka: Kiev, Ukraine, 1973.

29. Lesko, A.; Navara, E. Microstructural characterization of high-carbon ferrochrome. Mater. Charact. 1996, 36, 349-356. [CrossRef]

30. Liu, S.; Zhou, Y.; Xing, X.; Wang, J.; Ren, X.; Yang, Q. Growth characteristics of primary M7C3 carbide in hypereutectic Fe-Cr-C alloy. Sci. Rep. 2016, 6, 32941. [CrossRef] [PubMed]

31. Villieras, F.; Yvon, J.; Cases, J.M.; Donato, P.D.; Lhote, F.; Baeza, R. Development of microporosity in clinochlore upon heating. Clays Clay Miner. 1994, 42, 679-688. [CrossRef]

(C) 2018 by the authors. Licensee MDPI, Basel, Switzerland. This article is an open access article distributed under the terms and conditions of the Creative Commons Attribution (CC BY) license (http:/ / creativecommons.org/licenses/by/4.0/). 